\title{
Private Sector and Public Mental Health in India
}

\author{
Devashish Konar \\ MD, Consultant Psychiatrist \& Director, Mental Health Care Centre, Burdwan \& Kolkata \\ West Bengal, India. E-mail : devkon59@yahoo.com
}

India is a large country with huge population. Financial status of majority is not good enough to support quality treatment. Without good planning it may not be possible to reach health care to total population.

Healthcare in India essentially comprises three segments. The first segment consists of the government-sponsored public health system, which includes government hospitals, primary and secondary health centres, and nutritionrelated centres such as mid-day meal centres like anganwadis. The second segment consists of the high cost private sector healthcare which has expanded as a major enterprise opportunity everywhere in the country, especially metro cities. The third segment is a bridge between the first and second. It consists of healthcare which is private in ownership but is affordable, though often at the cost of quality. ${ }^{1}$

You can't deny the importance of private sector in health care. Latest NSS health survey says hospitalisation differences are 4 times-over $70 \%$ of rural and urban Indians get themselves treated at private sector facilities. The public sector simply doesn't have the funds to develop the kind of healthcare that India needs. Most of the developing countries spend more on health than India. ${ }^{2}$

Idea of community mental health in India is relatively new in India. Till 25 years back mental health had been restricted to the level of academic institutions, mental hospitals and few private clinics in India. The major criticism of present day health care is that it does not serve the people who need it most. The millennial demand is to reach the advancement of brain science to the broader humanity. Knowledge which does not serve the real people in need is more like an ornament than a utility.
Private sector actually serves an important role in public mental health. The problem of private sector is that it does not have any planning or guidance by the state and so develop unevenly and haphazardly. There are no incentives or relaxations for running services in unreached areas. We need to formulate them in consultation with the stake holders.

Magnitude of mental health problem is huge. The scale of the global impact of mental illness is substantial, with mental illness constituting an estimated $7.4 \%$ of the world's measurable burden of disease. The lack of access to mental health services of good quality is profound in populations with limited resources, for whom numerous social hazards exacerbate vulnerability to poor health. ${ }^{3}$

The aggregate burden of Years Lived with Disability (YLDs) resulting from mental and behavioral disorders $(22.7 \%)$ continues to be higher than that resulting from any other disease category. Yet the game changing potential of these empirical data to increase global investments in mental health care in proportion to the size of the problem has not been realized. Instead, vast gaps in resources persist and seriously compromise access to care. ${ }^{3}$

We must getdown to earth and to the root of the problem. Partnerships among governments, nongovernmental organizations, multilateral agencies, and academia can help to increase the capacity of the mental health workforce. Nonetheless, mere incremental augmentation of the workforce alone is unlikely to close the human resource gap. With the present capacities to recruit and train mental health professionals and the prevailing models of mental health care delivery, it cannot meet the gap in fore-seeable future. ${ }^{3}$ 
So how do we meet the gaps? In addition to training more mental health specialists, it is essential to make better use of their expertise by instituting enhancements and innovations that will increase the quality, relevance, and reach of clinical training. Resolving the gaps in human resources, for example, will probably entail the use of non-specialists to deliver mental health interventions. This change will call for fresh approaches to training that anticipate the evolution of more prominent supervisory and consultative roles that can leverage the scarce supply of expertise in mental health specialties. The contribution of the specialists must go beyond that of direct service delivery. Rigorous evaluations of the effectiveness of training is very important. ${ }^{3}$

In 2012, the report from the Sixty-fifth World Health Assembly urged member states and the WHO director-general to take bold corrective actions. Mental health has arrived on the global health agenda; establishing it as a priority at the highest level, is essential to match aspiration to need ${ }^{3}$. Health minister Harsh Vardhan in 2014 launched India's first-ever National Mental Health Policy to provide universal psychiatric care to the population, 20 percent of which are likely to be suffering from some form of mental illness by $2020^{4}$.

Public private collaboration is the need of the day. Four out of five people in need of mental health services are not getting it or to be more direct we are not able to provide them with. The mhGAP Intervention Guide is one way out but if Government want to do it alone it will invariably fail again. Public private collaboration is the only rational solution.

Advocacy groups from both public and private sectorsneed to take up the issues of vital importance in the field of mental health, example being,mental health and poverty ${ }^{5}$, climate change and mental health ${ }^{6}$, right to mental health and parity with physical health, stigma and mental illness, mental health and human rights, mental health act and mental health policy, and capacity building in academic psychiatry. These are some such issues which need to be taken up urgently.
Now let us examine National mental health programme. The formulation of the NMHP, in 1982, was an important milestone in the development of mental health care in the country. Apart from expansion in the coverage to government facilities there is also need to involve the growing private sector psychiatryin the NMHP. The approach has to recognise the needsof the total population, utilizing the available community resources and involving the different sectors of the society if you want the coverage to improve effectively. ${ }^{7}$

Funniest part is poor utilization of funds. The funding of NMHP has grown over the three decades, with a significant proportion of the funds remaining unutilized ${ }^{7}$. All the private practitioners in psychiatry have plenty of time in the initial few years. Many of them cover quite remote places and do not have adequate earning. For training of general practitioners and health workers who will finally give shape to national mental health programme, you need to involve these young doctors who will be much more effective than the limited number government doctors who are placed relatively centrally. We should think in terms of utilising some of the funds to take private psychiatrist into the loop, who will do this job happily, who are otherwise also interested in connecting to the general practitioners and health workers for their own practice.According to India's $12^{\text {th }}$ five-year economic plan (2012-17), the total budget for the National Mental Health program is almost 5.4 billion rupees ( $\$ 88.4$ million). But much of this funding is likely to go unspent, because states vary in terms of their technical capacity to implement the program. ${ }^{8}$

Private public partnership in NMHP should be envisaged in true sense of the word and not just providing a lip service. People in government services feel overwhelmed due to their inadequate number and the immensity of the problem. If they incorporate the people of the private sectorand truly try to develop a model of public-private partnership they can become a major force who will be able to take the cause of National Mental Health Program forward to a much higher level. 
We need to be practical and assign bigger role to private sectors. If county considers the private practitioners also as its work force, its sense of failure in catering services will decrease to a great extent. After all these doctors are also trained at the cost of national exchequer. In the last ten years I have seen many remote areas of my state West Bengal being quite adequately covered by private practitioners in contrast to centrally located medical colleges by the government.

WHO's mental health action plan 2013-2020 in quite ambitious. The Mental Health Action Plan's goal is to promote mental well-being, prevent mental disorders, provide care, enhance recovery, promote human rights and reduce the mortality, morbidity and disability for persons with mental disorders 9 . As you can see it covers a wide landscape of total activities of mental health professionals. To succeed you need a greater work force and so it can't beachieved without involving the private sector. There has to be consolidated efforts to achieve its aim. If we can do it successfully here in India,the Indian model may become a guideline for the emerging economies.

\section{REFERENCE}

Abdul Kalam A.P.J and Singh S.P. (2015) Ensuring Healthy Nation for All, Advantage India from challenge to opportunity, Page No-70

Editorial (2015 July $412.20 \mathrm{am}$ ) : Curing healthcare, Lease out public hospitals to private providers, The Financial Express

Becker A.E. and Kleinman A. (2013) Mental Health and the Global Agenda, The New England journal of Medicine, $369: 66-73$

Vardhan H. (2014) Press Information Bureau Government of IndiaMinistry of Health and Family Welfare, Country's first ever Mental Health Policy unveiled Society needs to change perception on mental illness10-October-2014 13 : 40 IST

Boardman J. Dogra N. and Hindley P. (2015)Mental health and poverty in the UK-time for change, BjPsych International, volume 12, Number 2, P. 27-28

Maughan D.L. and Berry H. (2015)Mind games: standing by while the world ignores climate change, BjPsyche International, volume 12 , Number 2, P. 29-30

Wig NN, Murthy SR (2015) The birth of national mental health program for India, Indian journal of Psychiatry, $57: 315-319$

Seervai S. (2014) India's New Mental Health Policy : Radical, but Tough to Implement. The Wall Street Jounal, India. (http:/ / blogs.wsj.com/indiarealtime/2014/10/14)

Mental Health Action Plan 2013-2020, World Health Organization 2013, Geneva, Switzerland, ISBN 9789241506021 